\title{
NILAI DIDAKTIS PADA TEMBANG DOLANAN ANAK BERBAHASA JAWA DI DESA BANYUMAS KECAMATAN STABAT KABUPATEN LANGKAT
}

\author{
Oleh \\ Sintia Dewi (dewisintia76@gmail.com) \\ Dr. Abdurrahman Adisaputera, M.Hum.
}

\begin{abstract}
Abstrak
Penelitian ini bertujuan untuk mengupayakan dan mempertahankan kembali tembang dolanan anak berbahasa Jawa di Desa Banyumas beserta permainannya yang sudah mulai dilupakan dan tidak diketahui oleh anak-anak di desa tersebut. Upaya yang dilakukan adalah dengan mempertahankan tembang dolanan anak berbahasa Jawa dengan cara mencatatkan kembali tembang dolanan yang bersifat lisan kedalam bentuk tulisan. Pentingnya tembang dolanan beserta permainannya untuk anak-anak dikarenakan nilai pendidikan yang terkandung di dalamnya mengajarkan anak-anak agar memiliki nilai moral, nilai keagamaan, nilai sosial, dan nilai budaya yang baik. Pada penelitian ini masyarakat Jawa di Desa Banyumas adalah sumber datanya, dan datanya adalah tembang dolanan itu sendiri.

Metode yang digunakan pada penelitian ini adalah metode penelitian kualitatif yang bersifat deskriptif. Instrumen pada penelitian ini adalah peneliti sendiri, pengumpulan data dilakukanmelaluiwawancara di lapangankepadanarasumber. Dari hasil perolehan data dilapangan ditemukan lima tembang dolanan yang menggunakan bahasa Jawa secara keseluruhan, sebagian data tidak digunakan karena bukan tembang dolanan berbahasa Jawa secara keseluruhannya sebab terdapat sebagian bahasa Indonesia. Kelima tembang dolanan pada setiap baitnya mengandung nilai didaktis (pendidikan) yang berbedabeda dan mengajarkan tentang moral yang baik, kereligiusan, budaya, dan sosial yang dapat diketahui melalui analisis makna pada tembang dolanan.
\end{abstract}

Kata kunci: Folklor, Permainan, Tembang Dolanan, Makna, Nilai Didaktis.

\section{PENDAHULUAN}

Tembang Jawa di bagi dalam beberapa jenis yaitu tembang gedhe, tembang tengahan, tembang macapat, dan tembang dolanan (Haryono, 2008:122124).Tembang gedhe (tembang Kawi) berkembang pada jaman Hindu. Penggunaan bahasa pada tembang ini menggunakan bahasa Jawa Kawi. Tembang 
tengahan berkembang pada jaman akhir Majapahit, diciptakan dalam bahasa Jawa Tengah. Tembang macapat merupakan puisi rakyat, penyebarannya secara lisan dan telah turun-temurun. Penggunaan tembang macapat lebih menekankan unsur suara untuk menghibur dan maknanya hanya disampaikan sekilas. Tembang dolanan adalah lagu yang dinyanyikan dengan bermain-main atau lagu yang dinyanyikan dalam suatu permainan tertentu. Permainan yang dilakukan oleh anak-anak tersebut merupakan suatu kegiatan yang menyenangkan.

Tembang dolanan merupakan istilah bahasa Jawa yang berasal dari dua kata tembang dan dolanan. Tembang merupakan tuturan puisi Jawa yang disuarakan dengan menggunakan nada-nada atau titilaras dan irama. Sementara dolanan berasal dari kata dolan yang artinya main. Dalam hal ini, kata dolanan yang dimaksud adalah dolan yang artinya main, yang mendapat akhiran an, sehingga menjadi dolanan (Andayani, 2014:246).

Folklor menurut Jan Harold Brunvand (dalam Danandjaja, 1984:21) digolongkan dalam tiga kelompok berdasarkan tipenya, yaitu folklor lisan, sebagian lisan, dan bukan lisan. Tembang yang dilantunkan dan disebarkan dari mulut ke mulut, dari generasi ke generasi, dikategorikan dalam folklor lisan, yang merupakan tradisi lisan yang diwariskan secara turun-temurun. Menurut Jan Harold Brunvand (dalam Andayani, 2014:247) folklor sebagai tradisi lisan memiliki ciri-ciri yaitu penyebaran dan pewarisannya dilakukan secara lisan, bersifat tradisional, ada dalam versi-versi bahkan varian-varian yang berbeda, bersifat anonim, mempunyai bentuk berumus dan berpola, mempunyai kegunaan (function), dan bersifat polos dan lugu.

Salah satu genre dari folklor adalah folksong. Tembang dolanan termasuk ke dalam genre folklor yaitu folksongs yang dinyanyikan bersama-sama secara berkelompok dan dilakukan secara serentak dalam suatu permainan anak. Menurut Jan Harold Brunvand (dalam Maryaeni, 2009:187) tembang dolanan termasuk folksong adalah salah satu genre atau bentuk folklor yang terdiri dari kata-kata dan lagu, yang beredar secara lisan di antara anggota kolektif tertentu, berbentuk tradisional, serta banyak mempunyai varian. Tembang dolanan yang termasuk ke dalam folksongs merupakan permainan rakyat yang cenderung 
melibatkan banyak anak. Hal ini akan berdampak pada aspek yang bisa menumbuhkan rasa kooperatif, sosialitas, loyalitas, dan solidaritas (Koentjaraningrat dalam Maryaeni, 2009: 187). Permainan kolektif dengan melibatkan banyak anak sebagai pemainnya memiliki dampak positif, terutama dalam rangka mendapatkan nilai-nilai tertentu yang sangat mendukung dalam pengembangan kepribadiannya kelak. Nilai yang terkandung dalam tembang dolanan salah satunya adalah nilai didaktis (pendidikan).

Menurut Sumardjo (1999:2) nilai-nilai dalam karya sastra merupakan hasil ekspresi dan kreasi estetik pengarang (sastrawan) yang ditimba dari kebudayaan masyarakatnya. Nilai ideal pengarang tersebut berupa das sollen tentang aspek nilai-nilai kehidupan, khususnya nilai-nilai pendidikan. Suatu karya sastra bisa dikatakan baik jika mengandung nilai-nilai yang mendidik.

Tembang dolanan sebagai suatu karya sastra mengandung nilai didaktis (nilai pendidikan) yang didalamnya terkandung pengajaran, keteladanan yang bermanfaat dan sebagai pedoman hidup bagi penikmatnya. Sumardjo (1999:3) mengungkapkan bahwa ada empat macam nilai pendidikan dalam sastra, yaitu nilai pendidikan religius, moral, sosial, dan budaya. Nilai-nilai tersebut tentunya tidak berbeda dengan nilai-nilai yang ada di kehidupan nyata sebuah masyarakat. Bahkan, nilai-nilai tersebut adalah nilai-nilai yang diidealkan pengarang untuk mengupas suatu masalah yang terjadi di kehidupan nyata. Nilai pendidikan tersebutlah yang menjadi acuan penulis sebagai kajian penelitian Tembang Dolanan di Desa Banyumas Kecamatan Stabat Kabupaten Langkat.

Desa Banyumas Kecamatan Stabat Kabupaten Langkat, merupakan daerah dengan mayoritas penduduknya bersuku Jawa. Menurut Badan Pemberdayaan Masyarakat Desa dan Kelurahan (BPMDK, 2015) Desa Banyumas Kecamatan Stabat Kabupaten Langkat di huni oleh 1.530 Kepala Keluarga (KK) total penduduknya 5.557 jiwa, dengan keterangan yaitu etnis Aceh 10 orang, Batak 14 orang, Nias 3 orang, China 10 orang, dan Jawa 5.520 orang. Kemayoritasan suku Jawa tersebut menjadikan tradisi Jawa mengakar kuat di masyarakat Desa Banyumas, termasuk tembang dolanan yang berkembang menjadi tradisi lisan yang di teruskan secara turun-temurun. Namun walaupun menjadi tradisi lisan, 
tembang dolanan saat ini sudah mulai tidak dimainkan oleh anak-anak di Desa Banyumas.

\section{METODE PENELITIAN}

Metode yang digunakan pada penelitian ini adalah metode penelitian kualitatif yang bersifat deskriptif yaitu penelitian yang menjelaskan dan menggambarkan makna dan nilai didaktis yang terdapat dalam tembang dolanan anak berbahasa Jawa. Menurut Mahsun (2009:235) metode penelitian kualitatif yang bersifat deskriptif merupakan strategi analisis dalam penelitian kualitatif yang lazim digunakan. Model analisis ini menggambarkan alur logika analisis data dan masukan bagi teknik analisis data yang digunakan.

Metode kualitatif digunakan untuk mendapatkan data yang mendalam, suatu data yang mengandung makna. Makna adalah data yang sebenarnya, data yang pasti merupakan suatu nilai di balik data yang tampak. Penelitian dengan menggunakan metode deskriptif kualitatif bertujuan untuk mengungkapkan kejadian atau fakta, keadaan, fenomena, variabel, dan keadaan yang terjadi saat penelitian berlangsung dengan menyuguhkan apa yang sebenarnya terjadi.

\section{HASIL DAN PEMBAHASAN PENELITIAN}

\section{A. Hasil Penelitian}

\section{Teks tembang dolanan anak berbahasa Jawa}

Teks tembang dolanan anak berbahasa Jawa didapatkan dari narasumber yang mengerti mengenai permainan dan arti dari tembang dolanan anak tersebut. Terdapat lima tembang dolanan yaitu Cublak-Cublak Suweng, Gotri Legendari, Gundhul Pacul, Jaranan, dan Slukhu-Slukhu Batok. Cublakcublak suweng merupakan tembang dolanan yang memiliki tujuh baris bait, tembang dolanan tersebut merupakan tradisi lisan yang pengarangnya dipercaya adalah wali songo atau bisa jadi tembang tersebut tidak diketahui siapa pengarangnya (anonim). Teks tembang dolanan Gotri Legendari memiliki lima baris bait, sesuai dengan tradisi lisan penyebaran dan pewarisannya dilakukan secara lisan, pengarang tembang dolanan tersebut 
tidak diketahui (anonim). Teks tembang dolanan Gundhul-Gundhul Pacul memiliki empat baris bait, sesuai dengan tradisi lisan penyebaran dan pewarisannya dilakukan secara lisan, pengarang tembang dolanan tersebut tidak diketahui (anonim). Teks tembang dolanan Jaranan memiliki sembilan baris bait, beberapa bait tembang merupakan onomatope yaitu bahasa yang diambil dari suara aktivitas hewan dan tidak memiliki arti, sesuai dengan tradisi lisan penyebaran dan pewarisannya dilakukan secara lisan, pengarang tembang dolanan tersebut tidak diketahui (anonim). Teks tembang dolanan Slukhu-Slukhu Batok memiliki lima baris bait, setiap bait memiliki arti yang menyiratkan tentang kereligiusan, sesuai dengan tradisi lisan penyebaran dan pewarisannya dilakukan secara lisan, pengarang tembang dolanan tersebut tidak diketahui (anonim).

\section{Makna yang Terkandung pada Tembang Dolanan}

Makna yang terkandung pada kelima tembang dolanan secara keseluruhannya yaitu mengajarkan anak-anak untuk memiliki nsikap jujur, rendah diri, amanah, menghormati orang tua, serta menghargai kehidupan. Tembang dolanan Cublak-Cublak Suweng memiliki makna untuk menanamkan sikap jujur kepada anak-anak, bahwa seseorang yang menyimpan sesuatu akan terlihat dari bagaimana perilakunya. Makna tembang dolanan Gotri Legendari menggambarkan tentang cita-cita dan tujuan hidup yang harus dimiliki setiap anak di masa dewasanya, bagaimana menjadi individu yang berguna bagi orang lain dan bagi dirinya sendiri.Makna tembang dolanan GundhulGundhul Pacul menggambarkan tentang amanah yang harus di emban oleh seorang pemimpin, bagaimana mensejehterakan rakyatnya, bijak dalam memimpin, dan rendah diri. Makna tembang dolanan Jaranan menggambarkan tentangbagaimana menjadi seorang pemimpin bukan berarti menjadikan seseorang menjadi anti untuk berbaur dengan rakyat atau orang dibawah kedudukannya.Makna tembang dolanan Slukhu-Slukhu Batok menggambarkan tentang penyesalan seseorang yang sudah mati atau meninggal karena menyianyia- kan masa saat masih hidup, kehidupannya hanya digunakan untuk mencari materi semata. 


\section{Nilai Didaktis yang Terkandung pada Tembang Dolanan Anak}

Nilai didaktis yang terkandung pada tembang dolanan anak mengharuskan anak-anak untuk memiliki nilai moral yang baik, nilai sosialisasi terhadap lingkungannya dan orang-orang sekitarnya, serta menanamkan nilai kereligiusan.

\section{Tabel 1 Hasil Penelitian}

\begin{tabular}{|c|c|c|c|}
\hline No & Tembang Dolanan & Makna & Nilai Didaktis \\
\hline 1 & Cublak-cublak suweng & $\begin{array}{l}\text { Anting-anting merupakan } \\
\text { barang berharga yang identik } \\
\text { dengan wanita. Wanita } \\
\text { memiliki sikap yang pemalu, } \\
\text { sopan, santun, dan rendah diri, } \\
\text { sikap tersebutlah yang seharus } \\
\text { nya dapat dijunjung, dijaga } \\
\text { oleh setiap individu dari } \\
\text { masyarakat Jawa. Menanam- } \\
\text { kan sikap jujur kepada anak- } \\
\text { anak, bahwa seseorang yang } \\
\text { menyimpan sesuatu akan } \\
\text { terlihat dari bagaimana } \\
\text { perilakunya. }\end{array}$ & $\begin{array}{l}\text { - Nilai Pendidikan } \\
\text { Moral } \\
\text { - Nilai Pendidikan } \\
\text { Sosial }\end{array}$ \\
\hline 2 & Gotri Legendari & $\begin{array}{l}\text { Setiap orang diharuskan } \\
\text { memiliki tujuan dalam hidup, } \\
\text { bagaimana menjadi seseorang } \\
\text { yang berguna untuk dirinya } \\
\text { sendiri dan berguna bagi orang } \\
\text { lain. }\end{array}$ & $\begin{array}{l}\text { - Nilai Pendidikan } \\
\text { Moral }\end{array}$ \\
\hline 3 & Gundhul-gundhul pacul & $\begin{array}{l}\text { Menggambarkan tentang } \\
\text { seorang pemimpin, bagai- } \\
\text { mana seorang pemimpin harus } \\
\text { memiliki sikap yang bijak, } \\
\text { rendah diri, dan mampu } \\
\text { memegang amanah dari } \\
\text { rakyatnya. Memegang amanah } \\
\text { jabatan sebagai pemimpin } \\
\text { bukan alasan seseorang untuk } \\
\text { menjadi bersikap sombong. }\end{array}$ & $\begin{array}{l}\text { - Nilai Pendidikan } \\
\text { Moral }\end{array}$ \\
\hline 4 & Jaranan & $\begin{array}{l}\text { Tuan Bei } \text { merupakan } \\
\text { bangsawan Jawa, yang diikuti } \\
\text { oleh para pelayannya. Sebagai } \\
\text { seorang yang } \quad \text { memiliki }\end{array}$ & $\begin{array}{l}\text { - Nilai Pendidikan } \\
\text { Moral } \\
\text { - Nilai Pendidikan } \\
\text { Sosial } \\
\end{array}$ \\
\hline
\end{tabular}




\begin{tabular}{|c|c|c|c|}
\hline & & $\begin{array}{l}\text { kedudukan terhormat, sikap } \\
\text { yang ditunjukkan Tuan Bei } \\
\text { adalah sikap rendah diri, ia } \\
\text { juga dihormati oleh rakyatnya. } \\
\text { Sikap rendah dirinya sebagai } \\
\text { seorang yang memiliki } \\
\text { kedudukan tinggi yaitu ia } \\
\text { tidak segan untuk datang ke } \\
\text { jalan-jalan rakyatnya. Menjadi } \\
\text { seorang pemimpin bukan } \\
\text { berarti menjadikan seseorang } \\
\text { menjadi anti untuk berbaur } \\
\text { dengan rakyat atau orang } \\
\text { dibawah kedudukannya. }\end{array}$ & \\
\hline 5 & Sluku-sluku bathok & $\begin{array}{l}\text { Makna pada tembang ini } \\
\text { menjelaskan tentang bagai- } \\
\text { mana penyesalan seseorang } \\
\text { yang sudah mati atau } \\
\text { meninggal karena menyianyia- } \\
\text { kan masa saat masih hidup, } \\
\text { kehidupannya hanya diguna- } \\
\text { kan untuk mencari materi } \\
\text { semata. }\end{array}$ & $\begin{array}{l}\text { - Nilai Pendidikan } \\
\text { Religi }\end{array}$ \\
\hline
\end{tabular}

\section{B. Pembahasan Penelitian}

\section{Teks Tembang Dolanan Anak Berbahasa Jawa}

1.1 Teks tembang dolanan Cublak-Cublak Suweng yaitu

Cublak-cublak suweng

Suwenge ting gelenter

Mambu ketundeng gudel

Pak empong lera-lere

Sapa ngguyu ndelikake

Sir sir pong dhele kosong

Sir sir pong dhele kosong

1.2 Teks tembang dolanan Gotri Legendari yaitu

Gotri olo gotri nagasari

Tiwul owal awul jenang katul

Nek gedhi dadi opo 
Sedengklok ela elo

Dadhi kodok

1.3Teks tembang dolanan Gundhul Pacul yaitu

Gundhul-gundhul pacul cul, gemblelengan

Nyunggi nyunggi wakul kul, gemblelengan

Wakul ngglimpang segane dadi sakratan

Wakul ngglimpang segane dadi sakratan

1.4Teks tembang dolanan Jaranan yaitu

Jaranan-jaranan

Jarane jaran teji

Sing numpak ndara Bei

Sing ngiring para mantri

Jeg jeg nong, jeg jeg gung

Jarane mlebu neng lurung

Gedebug krincing gedebug krincing

Gedebug krincing prok prok

Gedebug jedher

1.5Teks tembang dolanan Slukhu-Slukhu Batok

Sluku-sluku bathok

Bathoke ela-elo

Si rama menyang solo, oleh-olehe payung motha

Mak jenthit lolo lobah, wong mati ora obah

Nek obah medeni bocah, nek urip goleke dhuwit

\section{Makna yang Terkandung pada Tembang Dolanan}

1. Cublak-Cublak Suweng menggambarkan tentang penjagaan terhadap barang berharga, yaitu anting-anting yang merupakan barang berharga tersebut yang identik dengan wanita. Wanita memiliki sikap yang pemalu, sopan, santun, dan rendah diri, sikap tersebutlah yang seharus nya dapat 
dijunjung, dijaga oleh setiap individu dari masyarakat Jawa. Menanamkan sikap jujur kepada anak-anak, bahwa seseorang yang menyimpan sesuatu akan terlihat dari bagaimana perilakunya.

2. Gotri Legendari menggambarkan tentang cita-cita dan tujuan hidup yang harus dimiliki setiap anak di masa dewasanya, bagaimana menjadi individu yang berguna bagi orang lain dan bagi dirinya sendiri.

3. Gundhul-Gundhul Pacul menggambarkan tentang amanah yang harus di emban oleh seorang pemimpin, bagaimana mensejehterakan rakyatnya, bijak dalam memimpin, dan rendah diri.

4. Jaranan menggambarkan tentang bangsawan Jawa bernama Tuan Bei, yang diikuti oleh para pelayannya. Sebagai seorang yang memiliki kedudukan terhormat, sikap yang ditunjukkan Tuan Bei adalah sikap rendah diri, ia juga dihormati oleh rakyatnya. Sikap rendah dirinya sebagai seorang yang memiliki kedudukan tinggi yaitu ia tidak segan untuk datang ke jalan-jalan rakyatnya. Menjadi seorang pemimpin bukan berarti menjadikan seseorang menjadi anti untuk berbaur dengan rakyat atau orang dibawah kedudukannya.

5. Slukhu-Slukhu Batok menggambarkan tentang penyesalan seseorang yang sudah mati atau meninggal karena menyianyia- kan masa saat masih hidup, kehidupannya hanya digunakan untuk mencari materi semata.

\section{Nilai Didaktis yang Terkandung dalam Tembang Dolanan Anak}

1. Nilai didaktis yang terkandung pada tembang dolanan Cublak-Cublak Suweng adalah nilai pendidikan moral, sosial, dan budaya. Nilai pendidikan moral yaitu mengenai nilai kejujuran, rendah diri, sopan santun, menghargai dan menjaga barang yang dimiliki. Nilai ini bertujuan agar anak-anak yang memainkan dan menyanyikan tembang dolanan mendapatkan pengajaran moral yang baik untuk kehidupan mereka di masa dewasanya. Nilai pendidikan sosial yaitu kebersamaan anak-anak dengan teman-temannya dan kehidupan sosial dengan lingkungannya. 
2. Nilai didaktis yang terkandung pada tembang dolanan Gotri Legendari adalah nilai pendidikan moral, nilai pendidikan ini mengajarkan kepada anak-anak untuk mencapai cita-citanya.

3. Nilai didaktis yang terkandung pada tembang dolanan Gundhul-Gundhul Pacul adalah nilai pendidikan moral, bagaimana menjadi seorang pemimpin yang amanah, pemimpin yang bijak, dan pemimpin yang bertanggung jawab, tanpa menjadi seorang pemimpin yang sombong.

4. Nilai didaktis pada tembang dolanan Jaranan adalah nilai pendidikan moral dan nilai pendidikan sosial, sebagai orang muda seharusnya menghargai dan menghormati orang yang lebih tua. Begitupun dengan orang tua yang seharusnya tetap berperilaku baik terhadap orang yeng lebih muda dan tidak sombong. Nilai pendidikan moral yang juga terkandung pada tembang dolanan ini yaitu sikap rendah diri seseorang yang memiliki kedudukan yang lebih tinggi.

5. Nilai didaktis yang terkandung pada tembang dolanan Slukhu-Slukhu Batok adalah nilai pendidikan religius, nilai ini berhubungan dengan hubungan antara manusia dengan Tuhan dan bagaimana seharusnya manusia menjalani kehidupannya. Nilai pendidikan religius ini mengajarkan manusia untuk mengingat kematian, bahwa selama masih diberikan kesempatan untuk hidup pikirkankan lah pula kehidupan setelah kematian.

\section{PENUTUP}

Berdasarkan hasil penelitian mengenai tembang dolanan di Desa Banyumas Kecamatan Stabat Kabupaten Langkat, diperoleh simpulan yaitu

1. Terdapat lima teks tembang dolanan yang keseluruhannya berbahasa Jawa yaitu tembang dolanan cublak-cublak suweng, gotri legendari, gundhulgundhul pacul, jaranan, dan slukhu-slukhu bathok. Kelima tembang dolanan tersebut merupakan tembang dolanan pengantar permainan anak yang cara permainannya membutuhkan 3-5 orang anak, sehingga mampu menumbuhkan sikap kebersamaan, keceriaan, toleransi sesama anak. 
2. Makna yang terkandung pada setiap tembang dolanan mengajarkan anak pada kebaikan

2.1 cublak-cublak suweng memiliki makna agar menjaga barang berharga.

Barang berharga yang dimaksud adalah sikap rendah diri, sopan, santun, yang harus dijaga oleh setiap individu.

2.2 gotri legendari memiliki makna perjuangan dalam menggapai cita-cita, bagaimana menjadi orang yang berguna untuk orang lain.

2.3 gundhul-gundhul pacul memiliki makna sindiran terhadap seseorang yang menjadi pemimpin bagi rakyatnya, amanah yang diemban oleh pemimpintersebut haruslah di atas kepentingan rakyatnya, serta pelarangan memiliki sikap sombong.

2.4 jaranan memiliki makna sikap rendah diri yang dimiliki seseorang berkedudukan tinggi, serta penghormatan masyarakat kepada orang yang lebih tua, dan sikap bersosialisasi.

2.5 slukhu-slukhu bathok memiliki makna bagaimana menjalani kehidupan tanpa melupakan kehidupan setelahnya yaitu akhirat, serta bagaimana seseorang diharuskan tetap mengingat Tuhan.

3. Nilai didaktis merupakan nilai pendidikan, menurut Jacob Sumardjo nilai didaktis terbagi menjadi empat bagian yaitu nilai pendidikan religius, nilai pendidikan moral, nilai pendidikan sosial, dan nilai pendidikan budaya. Nilai didaktis terdapat pada tembang dolanan sebagai berikut

3.1 cublak-cublak suweng keseluruhan pada baitnya memiliki nilai pendidikan moral.

3.2 gotri legendari keseluruhan pada baitnya memiliki nilai pendidikan moral.

3.3 gundul-gundul pacul keseluruhan pada baitnya memiliki nilai pedidikan moral.

3.4 jaranan keseluruhan pada baitnya memiliki nilai pendidikan moral dan nilai pendidikan sosial.

3.5 sluku-sluku batok keseluruhan pada baitnya memiliki nilai pendidikan religi. 
Berdasarkan hasil penelitian dan simpulan di atas, saran yang dapat disampaikan yaitu penelitian ini diharapkan mampu memberikan kontribusi positif kepada masyarakat Jawa terutama masyarakat di Desa Banyumas untuk tetap melestarikan tradisi lisan yaitu permainan anak dengan tembang dolanan sebagai pengantar permainannya, yang telah diturunkan secara turun temurun karena memiliki manfaat dan nilai pendidikan yang baik untuk menumbuhkan sikap kebersamaan sesama anak-anak.

\section{Daftar Pustaka}

Achmad, Sri Wintala. 2016. Petuah-Petuah Leluhur Jawa. Yogyakarta: Araska.

BPMDK. 2015. Daftar Isian Profil Desa. Langkat.

Danandjaja, James. 1984. Folklor Indonesia: Ilmu Gosip, Dongeng, dan lain-lain. Jakarta: Grafiti Pers.

Maryaeni. 2009. Kajian Tembang Dolanan Dan Implikasinya Dalam Pendidikan Budi Pekerti Anak Bangsa Pada Pendidikan Dasar Dan Menengah. Jurnal Pendidikan Dan Pembelajaran. Vol. 16 No. 2 (187-193).

Sugiyono, 2011. Metode Penelitian Kuantitatif, Kualitatif dan R\&D. Bandung: Afabeta.

Sumardjo, Jacob. 1999. Konteks Sosial Novel Indonesia 1920-1977. Bandung: Penerbit Alumni. 